\title{
Comment
}

\section{What approach to property rights?}

\author{
CLAUDE MÉNARD* \\ Centre d'Économie de la Sorbonne, Université de Paris (Panthéon-Sorbonne), Paris, France
}

\begin{abstract}
In his rich contribution, Arruñada (2017) debates what institutions are needed to enforce complex 'sequential' transactions embedded in interdependent private contracts, and more specifically discusses the conditions of their efficiency when it comes to transferring property. Beyond acknowledging the importance of this issue and the very stimulating and often counterintuitive ideas developed in the paper, this short note challenges some of the positions adopted by Arruñada, particularly regarding the relevance of 'The problem of social cost' (Coase, 1960) for dealing with this issue. It also raises questions about the institutional, hybrid arrangement advocated as the solution for dealing with sequential transactions.
\end{abstract}

\section{Introduction}

Arruñada's paper (Arruñada, 2017) is looking for effective institutions to secure the transfer of property when it comes to enforcing the complex 'sequential' transactions characterized by interactions among contracts while eradicating as many externalities as possible. It is full of stimulating and often counterintuitive ideas. Abundant footnotes almost provide a paper of their own: they qualify statements, provide complementary elements, deliver counterexamples, etc., so much that the reader regrets not having them integrated and developed within the full body of the paper, notwithstanding space constraints.

The paper delivers its central message through issues related to property law. Not being a legal scholar, my understanding of its often provocative arguments is that they intend to answer two very substantial questions:

(1) What characterizes 'sequential exchange'? In Arruñada's words (\#4.2), ${ }^{1}$ the underlying assumption is that such a transaction 'poses an additional problem that requires a wider scope of impartiality than mere contractual enforcement of single-exchange' (à la Coase).

(2) What relevant institutions can make such sequential transactions enforceable and efficient? According to Arruñada, the Coasian focus on 'single exchange' (bilateral contracts) has introduced biases ('overemphasizing the initial allocation of rights, paying little attention to legal rights, and overestimating

*Email: claude.menard@univ-paris1.fr

1 Paragraph numbers refer to Arruñada (2017). 
the power of private ordering' $)^{2}$ that make it unsuitable as an adequate foundation to the law and economics of property.

Notwithstanding my deep sympathy for this important contribution, I hereafter discuss and challenge some answers and their foundation.

\section{Should we forget Coase?}

Arruñada considers the question of 'sequential exchange', which he identifies as 'interactions between contracts' (e.g. chains of titles), as central to the theory of property law. It is therefore no surprise that his starting point is Coase (1960). Referring to the classic examples provided in that paper (e.g. transactions between farmers and ranchers), he argues that the resulting focus on 'single exchange' by Coase and his followers has introduced a misleading approach to the analysis of property rights. The point he makes is that in addition to this two-party world of contracts, a large set of transactions amounts to a 'sequential exchange', which produces 'exchange externalities', distinct from 'use externalities' in that they arise out of the interactions among transactions. Note that although he criticizes the concept of property formalized by Alchian (1965) and others as the rights to make use of goods or services, which can be considered the foundation of the Coasian theory of property rights (Allen, 2015: 382), Arruñada remains vague about his own definition. His main concern is to demarcate his analysis from the purely (bilateral) contractual approach initiated by Coase.

In that respect, let me make three specific comments.

First, the fact that Coase (1960) does not provide all the tools needed to 'capture' sequential exchanges does not mean that his approach is irrelevant. Admittedly, 'To make his point about the importance of transaction costs, Coase (1960) does not need to consider if the entitlements under discussion are in rem or in personam' (\#3). So why not consider the analysis of bilateral contracts for what it is: a starting and innovative way to introduce the idea that there are costs in using alternative modalities to transfer rights, and that these costs must be assessed comparatively if an efficient allocation of resources is to be reached. After all, this is part of the story that Arruñada wants to tell. His very interesting distinction between administrative registries and contractual registries (\#7) unambiguously posits contracts as part of the picture. So why not consider the Coasian approach as an initial step, rather than the end of the story?

Second, why not take 'The problem of social cost' at its face value and consider this paper, as Coase did, as a first step to studying the 'influence of the law on the working of the economic system' (Arruñada, quoted in Coase, 1988: 10)? The question then becomes: shall the one-shot game between two players, on

2 Introduction and sections 6, 7 and 8 . 
which Coase focused, 'be abandoned for exploring the structure of property law' (\#3)? On the one hand, not all transactions are sequential and many contracts are bilateral. On the other hand, contracts remain important modalities for transferring property rights (including over land, etc.), so that 'exchange-related externalities' complement, rather than substitute, 'use externalities': again a point that Arruñada seems to acknowledge (\#7). More attention should then be paid to how the two dimensions are articulated, and what impact this interdependence has on property law. Is this not part of the challenging conflict that Arruñada points out between the freedom of contracts and the externalities generated by 'sequential exchange' motivating public intervention? In that sense one can argue that Arruñada is dealing with a different problem from the one addressed by Coase (1960): he focuses on the transfer of property over land while Coase was looking at negotiations among holders of property rights to make their usage efficient.

Third, it is surprising that Arruñada would begin his paper with the assumption of zero transaction costs (\#2), an approach that Coase fiercely rejected, as he is fully aware. Indeed, it is precisely because these costs are positive, which is assumed in the rest of Arruñada's paper, that externalities must be faced in 'sequential exchange' as well as in 'single exchange', making transaction costs and their institutional embeddedness central to the reasoning, which was exactly the central issue in Coase (1960). In that respect, Arruñada remains deeply Coasian!

These remarks do not deny the value of Arruñada's effort to capture the specific aspects of 'sequential exchange'. Actually, his reasoning may even carry a broader insight that goes beyond 'sequential exchange' and its role in the entitlement of property rights. For instance, interactions among contracts are relevant for understanding multilateral transactions (e.g. in a supply chain system), even when they are not sequential. My disagreement is rather with the statement that the 'single exchange' à la Coase would be a misleading starting point. Arruñada raises an important and very difficult problem (how to secure multilateral or sequential or overlapping transactions), which differs from the one considered by Coase (what institutions are needed to reallocate rights efficiently when transaction costs are positive?). The answer provided in 'The problem of social cost' (Coase, 1960) is that as soon as such costs exist (almost always), bilateral contracts no longer suffice; this is why institutions, namely the legal system in the 1960 s paper, enter the picture. ${ }^{3}$ In that respect, Arruñada's

3 'Furthermore we have to take into account the costs involved in operating the various social arrangements (whether it be the working of a market or of a government department), as well as the costs involved in moving to a new system. In devising and choosing between social arrangements we should have regard for the total effect. This, above all, is the change in approach which I am advocating' (Coase, 1960: 44). 
statement that 'a purely contractual solution to exchange externalities is hardly viable' opens to developments that are very much ... Coasian!

\section{What institutions are relevant?}

Once it is agreed that we live in a world of positive transaction costs, the next question (for Arruñada as well as for Coase) is what institution(s) can effectively reduce externalities in different contractual contexts ('single exchange' versus 'sequential exchanges')? Arruñada understands institutions as arrangements that can support a 'functional market economy' (Arruñada, 2017: footnote 22). Through numerous contributions over the years he has paid particular attention to what North (1991) called 'formal' institutional rules and constraints, with a special emphasis in the case of property law on potential institutions that could implement and efficiently monitor registries (operating under different forms, e.g. 'German registration', 'American recordation', etc.). The underlying reasoning is that while 'single exchange' transaction costs can be 'internalized by the parties themselves' (\#4, introduction; it should be clear from the above that I disagree), “"exchange externalities” are hardly contractible because they affect strangers to the transactions' (Arruñada, 2017: \#4). Three modalities are thereafter assessed in a very Coasian way, focusing on comparative rather than absolute performance' (Arruñada, 2017: footnote 16).

A purely private order based on reputation and benefits expected from future trade assumes repeated games among the same parties and can hardly suffice to deal with sequential transactions (Arruñada, 2017: footnote 13). I agree with Arruñada that beside the risks of fraud and forgeries, the very existence of multiple chains of title (or, more generally, transactions) creates information asymmetries that put prospective acquirers at risk of being defeated by the title of an unknown claimant (\#4.1). Numerous transactions are not repeated, and/or do not involve the same players, and/or are repeated on a time scale that does not allow to develop. For example, for most of us, buying a piece of land or a house is a rarely repeated transaction that can hardly rely solely on the reputation of the seller (or even intermediaries such as real estate agents). Unfortunately for the ignorant reader, Arruñada (2017: footnote 11) mentions limitations to private ordering with a reference to historians, without providing any detail.

So, 'use externalities' and 'exchange externalities' both require other institutions. What can they be? Here, we enter moving terrain, as acknowledged by Arruñada (\#5), with difficulties we all share. Since no private actor can have access to all contracts, producing information about potentially secret contracts requires 'public' intervention (conclusion, \#4.1). Weirdly enough, Arruñada defines a public solution as one that 'involves strangers to the intended transaction' (\#4.2). This definition is clearly unsatisfactory. A recent example illustrates. There is an ongoing and heated debate in Egypt about divorce: 
according to Sharia, an announcement by a husband to a third party ('stranger' to the 'contract') of his divorce has legal force even if his wife is not notified (in fact she need not be notified until quite a while after the decision). If we adopt a more conventional definition, which Arruñada follows thereafter with some ambiguity, a purely public solution, for instance registration entirely monitored by an administration, suffers from the inefficiencies and delays routinely associated with public bureaucracies (which can also plague private organizations; see Arruñada, 2017: footnotes 16 and 20, respectively).

Arruñada then turns his attention to hybrid solutions, combining the role of public authorities (administrative registration) with market-like mechanisms (contract registration?). The idea would be to create 'flexible public-private interfaces with the bureaucracies in charge of the public core of formalization services while allowing the free market to organize a multifaceted intermediate sector' (end of \#7). ${ }^{4}$ I am sympathetic to this idea. But Arruñada needs to go much further to make this solution clear and convincing. Although substantial knowledge about hybrid arrangements at the micro level has been accumulated (Ménard, 2013), when it comes to hybrid solutions at the macroinstitutional level, as promoted by Arruñada, the concept and connection to actual solutions remain much more obscure. What exact combination of public and private elements is at stake? What are the enforcement mechanisms, particularly on the market side of the equation? Is coordination guaranteed in the last resort by public authorities? Also, and this is very interesting, Arruñada points out the potential role of technological changes (the eruption of digitalization) in facilitating the accumulation, access, and diffusion of relevant information for parties to 'sequential exchange'. Would these technologies radically reduce the risk of hidden information and exchange externalities, thus diminishing transaction costs? Would they facilitate the 'integration' of administrative and contractual registration, a possibility that Arruñada discards as involving 'substantial risks' (\#7), without substantiating this statement? And who would secure these technologies and their usage in the last resort? It is easy to get the relevance and acuteness of these questions in our context, and it is one more merit of Arruñada to allow raising them.

\footnotetext{
4 On the private side, Arruñada gives the example of professional registering organizations (e.g. Depository Trust \& Clearing Corporation in the US). However he acknowledges that such private solutions are usually inadequate to deal with hidden information in chains of transactions. Actually, they play a limited role even with bilateral exchanges. For example the Dispute Resolution Corporation, the leading organization managing contractual disputes in the fruit and vegetable sector, had only 1,300 disputes submitted from 2000 to $2011 ; 85 \%$ were resolved through direct negotiation between parties or informal mediation by the DRC; only a handful of cases reached the arbitration stage (Gómez et al., 2012).
} 


\section{Conclusion}

Arruñada's paper raises very important issues regarding the institutional modalities that could support efficient transactions while reducing their costs when it comes to what he calls 'sequential exchange'. He argues that to deal with these issues relying on Coase (1960) is inadequate, even misleading. Although not an expert on property law, I think Arruñada is making important points about this issue of 'sequential exchange', and I have suggested that his contribution goes beyond the problems of property law and titles in transactions over land. However I disagree with his position on Coase. In my discussion, I argued that Arruñada is dealing with a different problem than the one raised in the 1960 paper, and that he is therefore demanding too much from a paper that opened an entire domain of research without pretending to explore it fully or to deliver the final word on the complex issue of property rights and their embeddedness in legal systems.

At stake in Arruñada's paper is our understanding of how to secure multilateral as well as sequential transactions. His emphasis on the importance of registries points to the more general role of what I suggested calling 'mesoinstitutions', those institutional arrangements that translate general rules into rules specific to different sectors and different transactions and are central in their enforcement (Ménard, 2014). As suggested about the 'hybrid' solutions advocated by Arruñada, a lot remains to be done to better understand the role of these intermediate layers in the institutional setting of market economies.

The urgency of this task is well illustrated by the challenging examples provided by Arruñada about how policies based on wrong premises can lead to more regulation and higher transaction costs. We must be grateful to Arruñada for pushing these very Coasian issues higher on our research agenda.

\section{References}

Alchian, A. A. (1965), 'Some Economics of Property Rights', Il Politico, 30(4): 816-29.

Allen, D. W. (2015) 'The Coase Theorem: coherent, logical, and not disproved', Journal of Institutional Economics, 11(2): 379-90.

Arruñada, B. (2017), 'Property as Sequential Exchange: The Forgotten Limits of Private Contract', published online. DOI: 10.1017/S1744137416000473.

Coase, R. H. (1960), 'The Problem of Social Cost', Journal of Law and Economics, 3(1): $1-44$.

Coase, R. H. (1988), The Firm, the Market, and the Law, Chicago: University of Chicago Press.

Gómez, M., M. Rizwan and K. Ricketts (2012), 'Origins, Creation, and Evolution of the Fruit and Vegetable Dispute Resolution Corporation', Report to the United States Department of Agriculture, Agreement \#12-25-A-5124. Last consulted: 26 January 2017. 
Ménard, C. (2013), 'Hybrid Modes of Organization: Alliances, Joint Ventures, Networks, and Other "Strange" Animals', in R. Gibbons and J. Roberts, The Handbook of Organizational Economics, Princeton: Princeton University Press, pp. 1066-108.

Ménard, C. (2014), 'Embedding Organizational Arrangements: Towards a General Model', Journal of Institutional Economics, 10(4): 567-89.

North, D.C. (1991), 'Institutions', Journal of Economic Perspectives, 5(1): 97-112. 